\title{
Antidepressant-like effects of kynurenic acid in a modified forced swim test
}

\author{
Masaru Tanaka $^{1,2} \cdot$ Zsuzsanna Bohár $^{1,2} \cdot$ Diána Martos $^{2} \cdot$ Gyula Telegdy $^{1,3} \cdot$ László Vécsei $^{1,2}$
}

Received: 16 July 2019 / Revised: 26 November 2019 / Accepted: 3 December 2019 / Published online: 12 March 2020

(c) The Author(s) 2020

\begin{abstract}
Background Kynurenic acid (KYNA) is an L-tryptophan metabolite with neuromodulatory activities, regulating the release of neurotransmitters such as glutamate, dopamine (DA), and acetylcholine (Ach). Dysregulation of the kynurenine pathway has been associated with neurodegenerative, neurological, and psychological disorders such as Alzheimer's disease, Parkinson's disease, Huntington's disease, major depressive disorder, and schizophrenia.

Methods The antidepressant-like effects of KYNA were studied with a modified mouse forced swimming test (FST), and the potential involvement of the serotonin (SER), norepinephrine, DA, Ach, $N$-methyl-D-aspartate, or gamma-aminobutyric acid subunit $A\left(\mathrm{GABA}_{\mathrm{A}}\right)$ receptors in its antidepressant-like effect was assayed by modified combination mouse FST. In combination studies, the mice were pretreated with the respective receptor antagonist, cyproheptadine $(\mathrm{CPH})$, phenoxybenzamine, yohimbine, propranolol, haloperidol (HPD), atropine, MK-801, or bicuculline (BCL).

Results The FST revealed that KYNA reversed immobility, climbing, and swimming times, suggesting the antidepressant-like effects of KYNA. Furthermore, the combination studies showed that CPH prevented the antidepressant-like effects of KYNA on immobility, climbing, and swimming times, whereas HPD reduced climbing time and BCL influenced immobility and climbing times and prevented the effects of KYNA on swimming time.

Conclusions The results demonstrated, for the first time, the presence of antidepressant-like effects of KYNA in a modified mouse FST. Furthermore, modified combination FST showed that the antidepressant-like actions of KYNA strongly interacted with 5-hydroxytryptamine type 2 SER-ergic receptors, weakly interacted with $\mathrm{D}_{2}, \mathrm{D}_{3}, \mathrm{D}_{4}$ DA-ergic receptors, and interacted moderately with $\mathrm{GABA}_{\mathrm{A}}$ receptors.
\end{abstract}

Keywords Tryptophan Kynurenine Kynurenic acid · Antidepressants · Neurotransmitter receptors · Depression

\section{Introduction}

Major depressive disorder (MDD) has been linked to imbalances of central nervous system (CNS) neurotransmitters such as serotonin (SER), norepinephrine (NE), dopamine (DA), acetylcholine (Ach), glutamate (Glu), and gamma $(\gamma)$-aminobutyric acid (GABA). Tryptophan

Masaru Tanaka

tanaka.masaru.1@med.u-szeged.hu

1 MTA-SZTE, Neuroscience Research Group, Szeged, Hungary

2 Department of Neurology, Interdisciplinary Excellence Centre, Faculty of Medicine, Albert Szent-Györgyi Health Centre, University of Szeged, Szeged, Hungary

3 Department of Pathophysiology, Faculty of Medicine, University of Szeged, Szeged, Hungary
(TRP) metabolism has been observed to play a role in the pathophysiology of MDD. 1-month treatment with a low TRP diet significantly increased the immobility time in the forced swim test (FST) in rats, suggesting the induction of depression-like behavior. Meanwhile, TRP depletion studies showed exacerbated mood symptoms in remittantly depressed patients, familiarly risk patients, and patients on anti-depressant drugs. Furthermore, supplements containing TRP have been reported to improve mood symptoms in MDD [1].

Kynurenic acid (KYNA) is a metabolite in the kynurenine (KYN) pathway from the essential amino acid LTRP, which is also a precursor of SER and melatonin in the melatonin pathway [2]. KYNA is a noncompetitive antagonist at the glycine site B of the $N$-methyl-D-aspartate (NMDA) Glu receptor, while quinolinic acid (QUIN) is an endogenous agonist at the NMDA receptor. Thus, 
the KYN pathway products, KYNA, and QUIN mutually influence neurotoxicity, excitotoxicity, cytotoxicity, and peroxidative actions at the NMDA receptor [3] (Fig. 1).

In this study, antidepressant-like effects of KYNA were studied and the potential involvement of the SER, NE, DA, Ach, NMDA, and GABA receptors in its antidepressant-like effect was investigated in a modified FST in mice. The mice were pretreated with a nonselective 5-hydroxytryptamine (5-HT) ${ }_{2}$ SER-ergic receptor antagonist, cyproheptadine (CPH), a nonselective alpha $(\alpha)$-adrenergic receptor (ADR) antagonist, phenoxybenzamine (PHB), an alpha-2 ( $\alpha 2)$-ADR antagonist, yohimbine (YHB), a beta ( $\beta$ )-ADR antagonist, propranolol (PPL), a $\mathrm{D}_{2}, \mathrm{D}_{3}, \mathrm{D}_{4} \mathrm{DA}$ receptor antagonist, haloperidol (HPD), a nonselective muscarinic Ach receptor antagonist, atropine (ATR), a noncompetitive NMDA receptor antagonist, MK-801 or a GABA subunit $\mathrm{A}\left(\mathrm{GABA}_{\mathrm{A}}\right)$ receptor antagonist, bicuculline (BCL).

\section{Materials and methods}

\section{Animals and ethical approval}

$\mathrm{CD}_{1}$ (Charles Dawley) male mice, generally employed as animal models in depression and kynurenine research, were kept and handled during the experiments in accordance with the guidelines of the 8th Edition of the Guide for the Care and Use of Laboratory Animals and the Use of Animals in Research of the International Association for the Study of Pain and the directive of the European Economic Community (86/609/ECC). The experiments

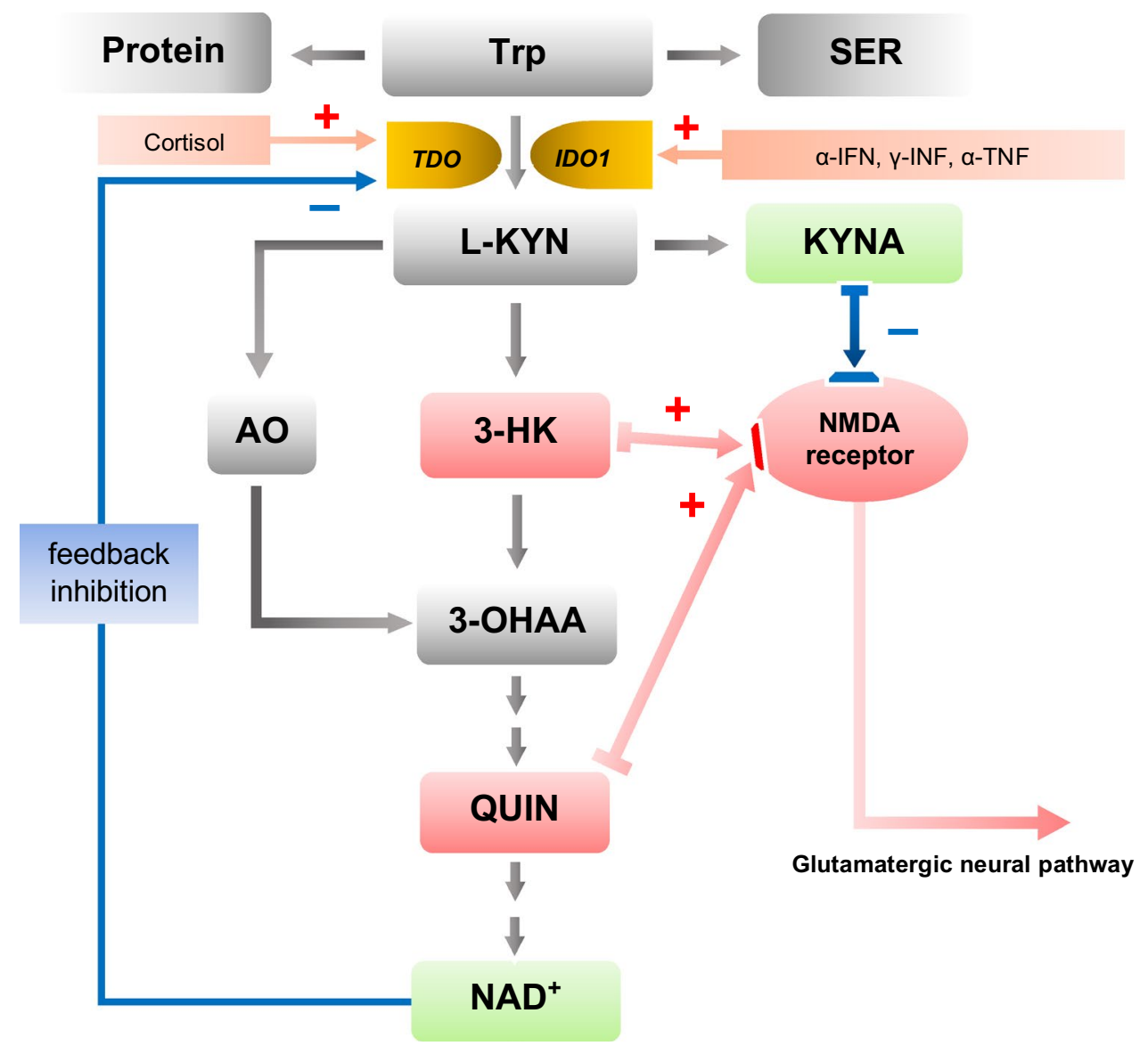

Fig. 1 The kynurenine pathway. More than 95\% of TRP is metabolized in the KYN pathway except for protein synthesis. More than $95 \%$ of TRP is converted by the hepatic rate-limiting TDO and the rest of TRP, by ubiquitous rate-limiting IDO1 and IDO2 to KYN. Cortisol induces TDO, while $\alpha$-IFN, $\gamma$-INF, and $\alpha$-TNF induce IDO1. $\mathrm{L}-\mathrm{KYN}$ is converted to AA, 3-HK, and KYNA. KYNA is an antagonist at NMDA receptor. AA and 3-HK are converted to 3-OHAA and further to QUIN. 3-HK and QUIN are agonists at NMDA receptor.
QUIN is converted to $\mathrm{NAD}^{+}$, which is a feedback inhibitor of TDO. TRP, tryptophan; SER, serotonin; TDO, tryptophan 2,3-dioxygenase; IDO, indoleamine 2, 3-oxygenase; IFN, interferon; TNF, tumor necrosis factor; KYN, kynurenine; KYNA, kynurenic acid; AA, anthranilic acid; 3-HK, 3-hydroxykynurenine; NMDA, $N$-methylD-aspartate; 3-OHAA, 3-hydroxyanthranilic acid; QUIN, quinolinic acid; $\mathrm{NAD}^{+}$, nicotinamide adenine dinucleotide 
were approved by the Committee of Animal Research at the University of Szeged (I.74-24/2018) and the Scientific Ethics Committee for Animal Research of the Protection of Animals Advisory Board (XI./240/2019). Each animal was used only once in the experiments. The animals were about 6 weeks old and weighed between 28 and $35 \mathrm{~g}$. They were housed under standard laboratory conditions at constant temperature $\left(25 \pm 1{ }^{\circ} \mathrm{C}\right)$ and on a 12-h dark-light cycle (lights on at 06:00-18:00 h) with free access to tap water and standard laboratory food. At least 1 week of recovery post-surgery was allowed before the experiments. The suffering of the animals and the number of animals used were kept to a minimum.

\section{Surgery}

To allow intracerebroventricular (icv) administration, a polystyrene cannula was implanted into the right lateral brain ventricle of each mouse at the coordinates $0.2 \mathrm{~mm}$ posterior, $0.2 \mathrm{~mm}$ lateral to the bregma, and $2.0 \mathrm{~mm}$ deep from the dural surface [4]. The cannula was fixed with cyanoacrylate (Ferrobond) (Budapest, Hungary). The $i c v$ administration was performed 5 days after the surgery.

\section{Materials}

KYNA was purchased from Sigma-Aldrich Corporation (St. Louis, MO, USA). CPH hydrochloride from Tocris (Bristol, UK); PHB hydrochloride from Smith Kline \& French (Herts, UK); YHB hydrochloride from Tocris (Cologne, Germany); PPL hydrochloride from ICI Ltd. (Macclesfield, UK); ATR sulfate from EGIS (Budapest, Hungary); HPD from G. Richter (Budapest, Hungary); MK-801 from Sigma-Aldrich Corporation (St. Louis, MO, USA) and BCL methiodide from Sandoz (Basel, Switzerland). KYNA was dissolved in sterile pyrogen-free $0.9 \%$ saline and administered $i c v$ via the cannula in a volume of $2 \mu \mathrm{l}$. Physiological saline $(0.9 \% \mathrm{NaCl})$ was used as a control.

\section{Forced swimming test}

The modified mouse FST was performed as reported previously [5]. The mice were placed individually in a glass cylinder of $12 \mathrm{~cm}$ in diameter and $30 \mathrm{~cm}$ in height. Water $\left(25 \pm 1{ }^{\circ} \mathrm{C}\right)$ was filled to a height of $20 \mathrm{~cm}$. Fresh water was used for each mouse. A 15 -min pretest was carried out $24 \mathrm{~h}$ before the 3-min test session. 30 min prior to the test session, KYNA was administered $i c v$ at a volume of $2 \mu \mathrm{l}$, at doses of $0.1 \mathrm{mM}, 0.5 \mathrm{mM}, 1.0 \mathrm{mM}, 1.5 \mathrm{mM}$ or $2.0 \mathrm{mM}$.
In the modified combination FST, 30 min prior to KYNA (2.0 $\mathrm{mM} i c v$ ) administration, the following receptor blockers were administered intraperitoneally (ip): $\mathrm{CPH}(3 \mathrm{mg} / \mathrm{kg}$ ip) $(N=15)$, PHB $(2 \mathrm{mg} / \mathrm{kg} i p)(N=15)$, YHB $(5 \mathrm{mg} / \mathrm{kg}$ ip) $(N=10)$, PPL ( $5 \mathrm{mg} / \mathrm{kg} i p)(N=10)$, HPD $(10 \mu \mathrm{g} / \mathrm{kg} i p)$ $(N=15)$, ATR $(2 \mathrm{mg} / \mathrm{kg}$ ip $)(N=15)$, MK-801 (2 mg/kg ip) $(N=10)$ or, BCL $(2 \mathrm{mg} / \mathrm{kg}$ ip $)(N=10)$. Physiological saline was used for the control. A time-sampling technique was conducted to count the duration of climbing, swimming, and immobility times.

\section{Open field test}

Locomotor activity was assayed by the open field test. The mice were placed individually in the center of a $35 \mathrm{~cm} \times 35 \mathrm{~cm}$ open-field box consisting of 49 squares. KYNA ( $2.0 \mathrm{mM} i c v)$ was administered $30 \mathrm{~min}$ before the exploratory test session, which lasted $3 \mathrm{~min}$. The total number of floor units entered, the number of occasions on which the animals stood on their hind legs and the number of occurrences of face washing, forepaw licking and head stroking, each of which indicated the ambulatory activity, the total number of rearing and the grooming frequency were monitored.

\section{Statistical analysis}

The analysis of variance (two-way ANOVA) test was followed by Tukey's test for multiple comparisons with unequal cell size. Probability values $(p)$ of less than 0.05 were regarded as indicative of significant differences.

\section{Results}

Compared to controls, a dose of $1.0 \mathrm{mM}$ KYNA significantly decreased immobility time $[F(3.35)=10.68, p<0.05]$. $1.5 \mathrm{mM}$ significantly decreased immobility time $[F$ $(3.35)=13.93, p<0.05]$ and significantly increased swimming time $[F(3.35)=6.73, p<0.05] .2 .0 \mathrm{mM}$ significantly decreased immobility time $[F(3.35)=14.98, p<0.05]$, significantly increased climbing time $[F(3.35)=7.75$, $p<0.05]$, and significantly increased swimming time $[F$ $(3.35)=11.10, p<0.05]$. The results suggest that KYNA induces antidepressant-like effects with doses of $1.0 \mathrm{mM}$, $1.5 \mathrm{mM}$, and $2.0 \mathrm{mM}$ (Fig. 2).

Pretreatment with $\mathrm{CPH}$ significantly increased immobility time and significantly decreased swimming time compared to KYNA. It suggests the possible involvement of the SER receptor in KYNA-induced antidepressant-like effects. Pretreatment with PHB did not reverse immobility, climbing, or swimming times compared to KYNA, thus the NE receptor may not be involved in KYNA-induced antidepressant-like 

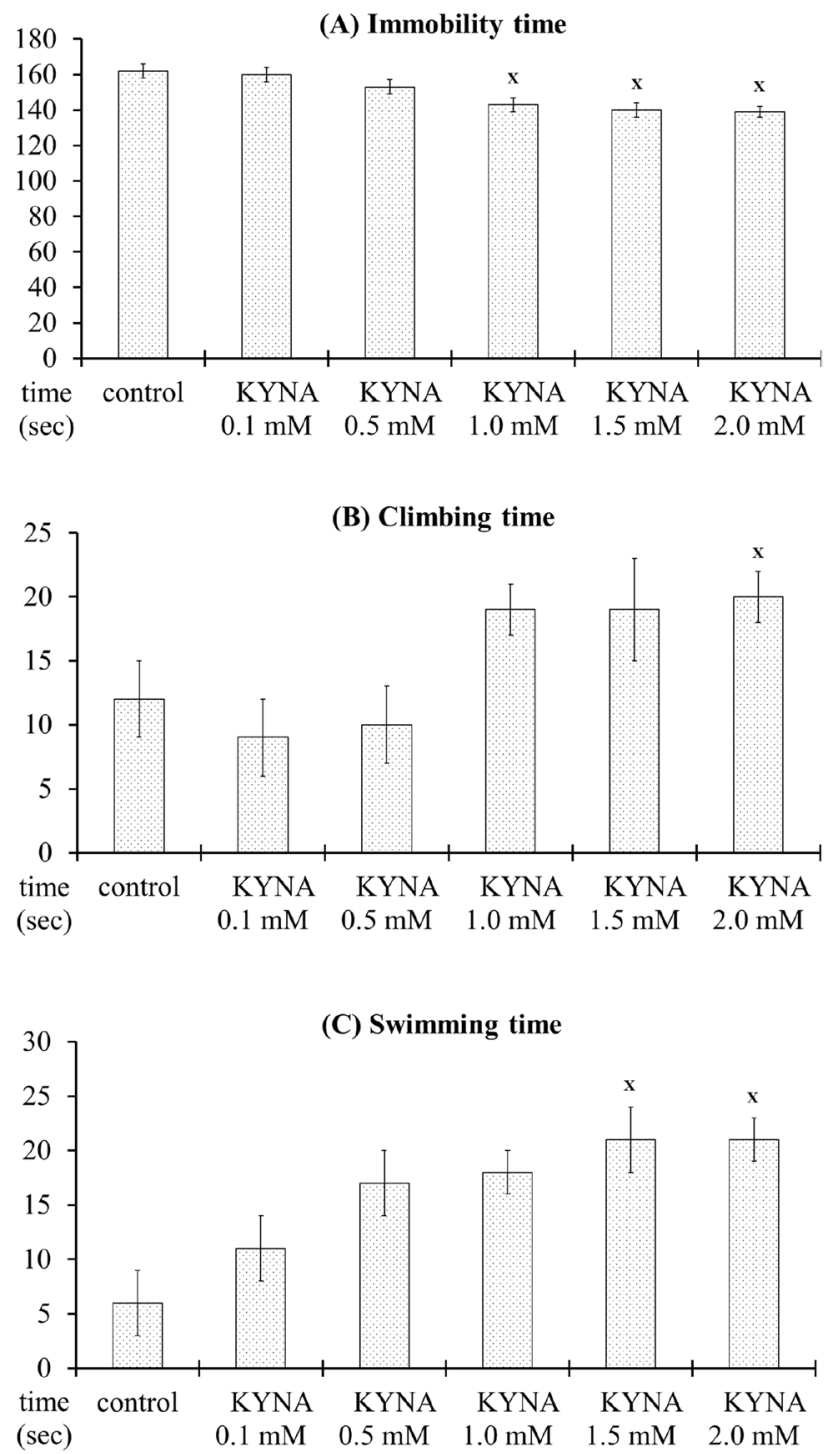

Fig. 2 The effect of kynurenic acid (KYNA) on immobility, climbing, and swimming times in a modified mouse forced swim test (FST). Compared to controls, KYNA significantly decreased immobility time in doses higher than $1.0 \mathrm{mM}$; significantly increased climbing time in a dose of $2.0 \mathrm{mM}$; significantly increased swimming time in doses of higher than $1.5 \mathrm{mM}$. Thus, KYNA showed the antidepressant-like effects in a modified mouse FST. Control $(N=12)$, KYNA $0.1 \mathrm{mM} i c v(N=12)$, KYNA $0.5 \mathrm{mM} i c v(N=12)$, KYNA $1.0 \mathrm{mM}$ icv $(N=12)$, KYNA $1.5 \mathrm{mM} i c v(N=12)$, KYNA $2.0 \mathrm{mM}$ icv $(N=12) . \times, p<0.05$ vs. control $(N$, the number of animals; $p$, probability)

effects. Likewise, pretreatment with YHB did not reverse immobility, climbing, and swimming times compared to KYNA, so the $\alpha 2$-ADR receptor also may not be involved in KYNA-induced antidepressant-like effects nor did pretreatment with PPL reverse climbing, swimming, and immobility times compared to KYNA, so the $\beta$-ADR receptor is not involved in KYNA-induced antidepressant-like effects. Pretreatment with HPD did not change the immobility or swimming times but did decrease climbing time compared to KYNA. It suggests a minimal involvement of the $D_{2}, D_{3}, D_{4}$ DA receptor in KYNA-induced antidepressant-like effects.

Pretreatment with ATR did not affect immobility, climbing, or swimming times compared to KYNA, so the muscarinic Ach receptor may not be involved in KYNA-induced antidepressant-like effects. Likewise, pretreatment with MK-801 did not affect climbing, swimming or immobility times compared to KYNA, thus the NMDA receptor may not be involved in KYNA-induced antidepressantlike effects. Pretreatment with BCL increased immobility time, decreased climbing time, and significantly decreased swimming time compared to KYNA, suggesting a possible involvement of the $\mathrm{GABA}_{\mathrm{A}}$ receptor in KYNA-induced antidepressant-like effects (Fig. 3).

No significant alterations in locomotive, rearing or grooming activities were observed following the $i c v$ administration of $2.0 \mathrm{mM}$ KYNA (data not shown).

The above results revealed the presence of antidepressantlike effects of KYNA in a modified mouse FST, and the antidepressant-like actions of KYNA strongly interacted with 5-HT ${ }_{2}$ SER-ergic receptors, weakly interacted with $\mathrm{D}_{2}$, $\mathrm{D}_{3}, \mathrm{D}_{4} \mathrm{DA}$-ergic receptors, and moderately interacted with $\mathrm{GABA}_{\mathrm{A}}$ receptors (Table 1).

\section{Discussion}

Disruption of the KYN pathway has been implicated in the pathophysiology of MDD [6]. The relationship between plasma KYN concentration and anxiety and depression in psychiatric patients has been studied. Plasma KYN concentration was increased in endogenous anxiety and decreased in endogenous depression. It was also observed that KYN, QUIN, and 3-hydroxy-KYN (3-HK) had anxiogenic effects, while KYNA was anxiolytic for mice in a dark-light chamber. Accordingly, it has been suggested that a group of KYN metabolites and neurokynurenines (NEKYs) are participants in depression $[6,7]$.

The SER hypothesis postulates that a deficit of SER in the CNS is the cause of MDD. TRP is the sole precursor of peripherally and centrally produced SER, and approximately 95 to $99 \%$ of dietary TRP not used in protein synthesis is metabolized in the KYN pathway. Thus, a small portion of TRP is available for SER-melatonin synthesis. Furthermore, it was proposed that SER deficiency in MDD was caused by a shunt of TRP metabolism from the formation of SER towards the production of KYN due to the activation of the hepatic rate-limiting enzyme, TRP 2,3-dioxygenase (TDO), which is activated by the primary stress hormone, cortisol. Activation of the ubiquitous rate-limiting enzyme, indoleamine 2, 3-oxygenase (IDO) 1 is induced by pro-inflammatory 

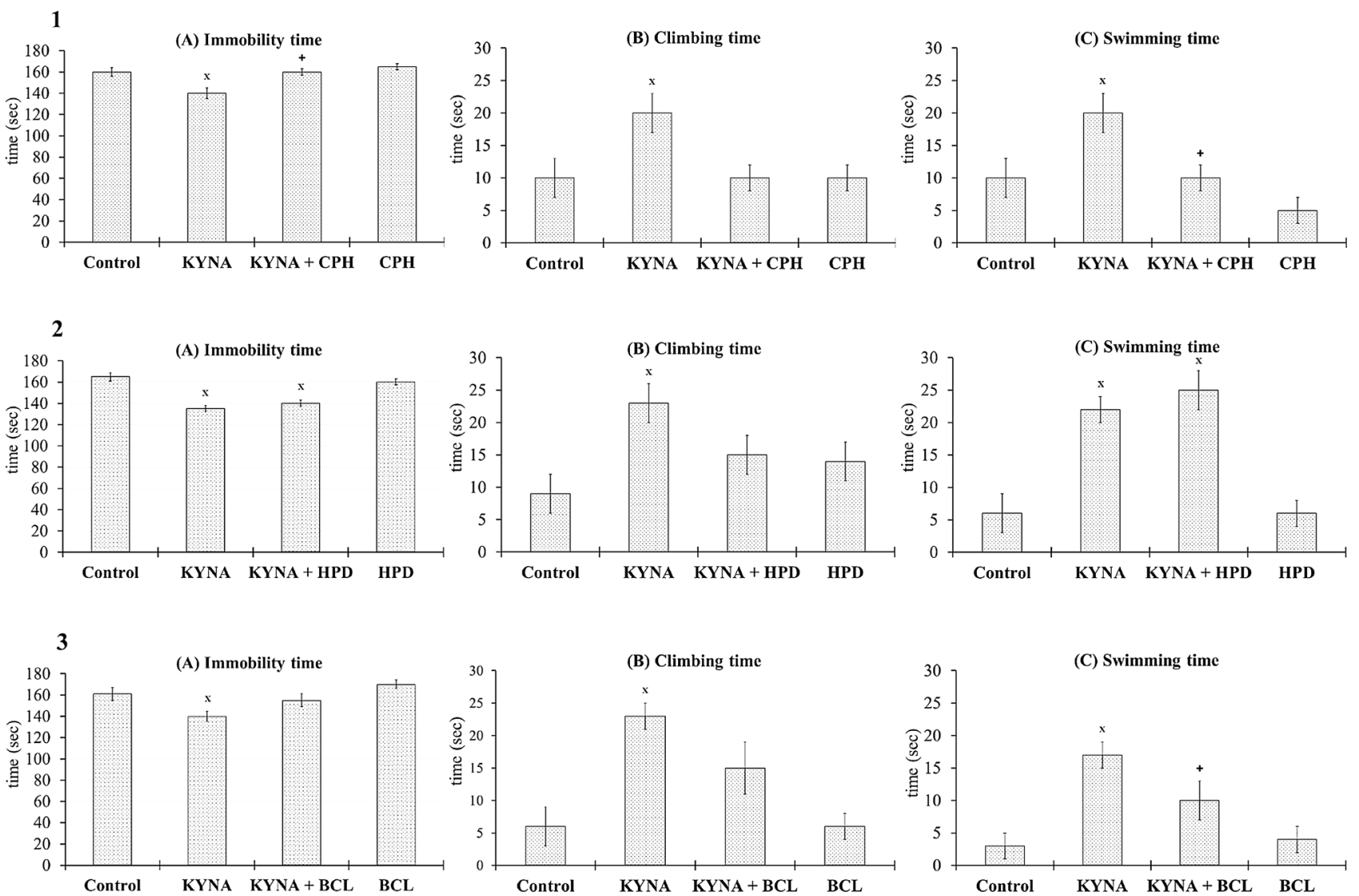

Fig. 3 The effect of a non-selective $5-\mathrm{HT}_{2}$ serotonergic receptor antagonist, cyproheptadine $(\mathrm{CPH})$, a $\mathrm{D}_{2}, \mathrm{D}_{3}, \mathrm{D}_{4}$ dopamine receptor antagonist, haloperidol (HPD) or a $\gamma$-aminobutyric acid subunit $\mathrm{A}$ receptor antagonist, bicuculline (BCL) in KYNA-induced antidepressant-like action in a modified mouse forced swim test. 1, CPH pretreatment significantly increased immobility time and significantly decreased swimming time compared to KYNA. This suggests a possible involvement of the SER receptor in KYNA-induced antidepressant-like effects. Control $(N=15)$, KYNA $2.0 \mathrm{mM}$ icv $(N=15), \mathrm{CPH}$ $3.0 \mathrm{mg}+\mathrm{KYNA} 2.0 \mathrm{mM} i c v(N=15), \mathrm{CPH} 3.0 \mathrm{mg} / \mathrm{kg}$ ip $(N=15) .2$, HPD pretreatment did not change immobility and swimming times, but decreased climbing time compared to KYNA. This suggests

cytokines such as $\alpha$-interferon (IFN), $\gamma$-IFN, $\alpha$-tumor necrosis factor, and so on [8, 9] (Fig. 1).

KYNA exhibited antidepressant-like effects by significantly decreasing immobility time, and significantly increasing climbing and swimming time in the modified FST in mice (Fig. 2). The icv administration of KYNA may overwhelm KYN, QUIN, and 3-HK actions at the NMDA receptors, resulting in the inhibition of the excitatory neuron pathway. The antidepressant-like effects of KYNA are reversed by the ip administration of SER antagonist, CPH. This suggests the possible involvement of SER receptors in the antidepressant-like effects of KYNA (Fig. 3; Table 1). It may also be assumed that the icv KYNA injection alters the KYN pathway balance, resulting in increased nicotinamide adenine dinucleotide $\left(\mathrm{NAD}^{+}\right)$, which is responsible for the a minimal involvement of the $\mathrm{D}_{2}, \mathrm{D}_{3}, \mathrm{D}_{4}$ DA receptor in KYNAinduced antidepressant-like effects. Control $(N=15)$, KYNA $2.0 \mathrm{mM}$ $i c v(N=15)$, HPD $10.0 \mu \mathrm{g} / \mathrm{kg} i p+\mathrm{KYNA} 2.0 \mathrm{mM}$ icv $(N=14)$, HPD $10.0 \mu \mathrm{g} / \mathrm{kg}$ ip $(N=15) .3$, BCL pretreatment increased immobility time, decreased climbing time and significantly decreased swimming time compared to KYNA. This suggests a possible involvement of the $\mathrm{GABA}_{\mathrm{A}}$ receptor in KYNA-induced antidepressant-like effects. Control $(N=10)$, KYNA $2.0 \mathrm{mM} i c v(N=10)$, BCL $2.0 \mathrm{mg} /$ $\mathrm{kg} i p+\mathrm{KYNA} 2.0 \mathrm{mM} i c v(N=10)$, BCL $2.0 \mathrm{mg} / \mathrm{kg}$ ip $(N=10), \times$, $p<0.05$ vs. control;,$+ p<0.05$ vs. KYNA, ( $N$ : the number of animals, $p$ : probability)

feedback inhibition of TDO. Thus it facilitates the shunt of TRP metabolism from the KYN pathways toward the SER pathways to increase SER production [10].

The descending Glu-ergic neural pathway projects from the prefrontal cortex (PFC) toward the brain stem areas, innervating the substance nigra $(\mathrm{SN})$, the ventral tegmental area (VTA), the midbrain raphe nuclei (MRN), and the locus coeruleus (LC). The VTA, MRN, and LC are the main brain areas where numerous serotonergic neurons originate $[11,12]$. Thus, the inhibition of Glu-ergic neurotransmission may coordinate proper SER-ergic neuron firing, leading to antidepressant-like actions.

Anhedonia is one of the main symptoms of MDD and has been linked to dysfunction of the reward system in which DA neurotransmission plays a significant role. Animal models 
Table 1 The involvement of receptors in KYNA-induced antidepressant-like action in modified combination mouse swim test

\begin{tabular}{llll}
\hline Receptors & \multicolumn{3}{l}{ Modified combination FST } \\
\cline { 2 - 4 } & Immobility & Climbing & Swimming \\
\hline $5-\mathrm{HT}_{2}$ serotonin & High & Low & High \\
$\alpha$-Adrenaline & - & - & - \\
$\alpha_{2}$-Adrenaline & - & - & - \\
$\beta$-Adrenaline & - & - & - \\
$\mathrm{D}_{2}, \mathrm{D}_{3}, \mathrm{D}_{4}$ dopamine & - & Low & - \\
Muscarinic acetylcholine & - & - & - \\
$N$-methyl-D-aspartate & - & - & - \\
Gamma-aminobutyric acid & Low & Low & High \\
subunit A & & & \\
\hline
\end{tabular}

The antidepressant-like actions of KYNA strongly interacted with 5-HT $\mathrm{H}_{2}$ SER-ergic receptors, weakly interacted with $\mathrm{D}_{2}, \mathrm{D}_{3}, \mathrm{D}_{4} \mathrm{DA}$ ergic receptors, and moderately interacted with $\mathrm{GABA}_{\mathrm{A}}$ receptors. "-": A receptor antagonist did not modify KYNA-induced antidepressant-like effects. "low": A receptor antagonist modified KYNAinduced antidepressant-like effects with $p>0.05$ vs. KYNA. "high": A receptor antagonist modified KYNA-induced antidepressant-like effects with $p<0.05$ vs. KYNA

of depression also demonstrate changes in the function for the mesolimbic DA system. Altered DA receptor expression within the limbic structures was observed in different models of depression, such as the learned helplessness model and the chronic mild stress model [13]. $\mathrm{A} \mathrm{D}_{2}, \mathrm{D}_{3}, \mathrm{D}_{4} \mathrm{DA}$ receptor antagonist, HPD, influenced the climbing time in the modified combination FST. This suggests that the KYNAinduced antidepressant-like action may possibly be involved in DA receptor function (Fig. 3; Table 1).

Main DAergic neural pathways involved in MDD originate in the SN and VTA, which project toward the striatum, PFC and amygdala. Glu-ergic neurons from the PFC innervate the SN and VTA and may influence the DA-ergic neurotransmission. Furthermore, Glu-ergic neural pathways innervate the striatum and amygdala as part of the cortico-striatum-thalamus loop, and thus may influence DA-ergic neural effectors $[11,12]$.

In humans, about $80 \%$ of neurons in the neocortex are spiny and excitatory and form $85 \%$ of the synapses, indicating that Glu neurons and synapses occupy the largest part of the brain governed by a Glu-ergic excitatory neurons. It was reported that 2-amino-7-phosphonoheptanoic acid, a competitive NMDA subtype of Glu receptor antagonist, MK-801, a noncompetitive NMDA antagonist and 1-aminocylopropanecarboxylic acid showed antidepressant-like effects in animal models [14]. Significantly higher cerebrospinal fluid (CSF) glutamine (Gln) concentrations were observed in MDD patients [15]. The findings are in accordance with antidepressant-like effects of KYNA as a NMDA receptor antagonist, which inhibits excitatory Glu-ergic neurotransmission.
Antidepressant-like effects induced by KYNA may be triggered by inhibition of the $\alpha 7 \mathrm{nAchR}$, leading to the reduction of Glu neurotransmitter, and by antagonistic inhibition of ionotropic AMPA, NMDA, and kainate subtypes of Glu receptors, present on presynaptic and postsynaptic neurons, as well as on glial cells, inhibiting rapid ionotropic effects. Noncompetitive NMDA receptor antagonist MK-801 did not affect KYNA-induced antidepressant-like action, showing that KYNA and MK-801 are not synergistic action at the NMDA receptors. A high dose of MK-801 is a potent antidepressant per se in FST. A lower dose was calibrated to study the modified FST in combination with its MK-801, but did not show any antidepressant effect in FST.

About $20 \%$ of the neurons are smooth and inhibitory and $15 \%$ of the synapses in the neocortex are occupied by GABA, which mediates fast inhibitory transmission. Deficits in GABA neurotransmission may contribute to MDD according to the findings of reduced GABA levels in plasma, CSF, and resected cortical tissue of MDD patients [15]. A significantly reduced behavioral reactivity in the open field and reduced glutamic acid decarboxylase mRNA expression in the limbic system were found in male rats on reboxetine, a NE reuptake inhibitor [16]. A significant increase in the occipital cortex GABA concentration was observed by proton magnetic resonance spectroscopy in MDD patients on fluoxetine, a selective SER reuptake inhibitor [17].

The GABA-ergic deficit hypothesis of depression suggests that the activation of the hypothalamus-pituitary-adrenal glands (HPA) axis is triggered by reduced GABA release in the hippocampus and frontal cortex, both of which are projecting to the paraventricular nucleus of the hypothalamus. That is, it is caused by reduced GABA-ergic synaptic inhibition in the HPA axis [18]. Other GABA-ergic neurons projecting toward the hypothalamus originate in NAc, where numerous neural pathways transit or destinate, including Glu-ergic neurons originating from the prefrontal cortex, amygdala, and hippocampus [11,12]. Marked alterations in $\mathrm{GABA}_{\mathrm{A}}$ receptor signaling are reported in both anxiety and mood disorders [19].

$A \mathrm{GABA}_{\mathrm{A}}$ receptor antagonist, BCL, influenced the immobility and climbing times and prevented the effects of KYNA on swimming time in the modified mouse FST. It suggests KYNA triggered antidepressant-like actions through the $\mathrm{GABA}_{\mathrm{A}}$ receptors (Fig. 3; Table 1). KYNAinduced antidepressant actions may be generated by shifting the Glu/GABA-Gin cycle in favor of more GABA production. Inhibitory GABA-ergic neurotransmission may be fine-tuned by a panel of neurotransmitters in the NAc; thus, it may help induce KYNA's antidepressant-like actions. But, the involvement of KYNA inhibition at presynaptic $\alpha 7 \mathrm{nAch}$ and the excitatory NMDA receptors triggering the 
GABA-ergic neurotransmissions, and GABA production has yet to be investigated.

Meta-analysis of animal and human studies comparing metabolite levels of the KYN pathway between patients with depression and healthy controls showed that KYNA and KYN levels were slightly decreased in patients with MDD, ratios of KYNA/QUIN, as well as KYNA/3-HK, were lower in patients with depression, and there were no differences in QUIN and 3-HK levels between the two groups, presenting a strong evidence that the KYN pathway is involved in the pathophysiology of MDD [20].

Much evidence supports the involvement of KYN pathway products, KYNA, and NEKYs in MDD. This work shows, for the first time, KYNA's antidepressant-like effects in a modified mouse FST. Furthermore, the antidepressantlike actions of KYNA interacted strongly with 5-HT 2 SERergic receptors, weakly with $D_{2}, D_{3}, D_{4}$ DA-ergic receptors, and in moderately with $\mathrm{GABA}_{\mathrm{A}}$ receptors. KYNA's beneficiary antidepressant-like actions are to be explored further in the search for a potential novel therapeutic agent against MDD.

Acknowledgements Open access funding provided by University of Szeged (SZTE). This work was funded by GINOP 2.3.2-15-201600034, Ministry of Human Capacities, Hungary Grant 20391-3/2018/ FEKUSTRAT and University of Szeged Open Access Fund (FundRef), Grant number 4639. We thank Ms. Jennifer Tusz, a native English speaker, for proofreading the manuscript.

\section{Compliance with ethical standards}

Conflict of interest There is no conflict of interest regarding this work.

Open Access This article is licensed under a Creative Commons Attribution 4.0 International License, which permits use, sharing, adaptation, distribution and reproduction in any medium or format, as long as you give appropriate credit to the original author(s) and the source, provide a link to the Creative Commons licence, and indicate if changes were made. The images or other third party material in this article are included in the article's Creative Commons licence, unless indicated otherwise in a credit line to the material. If material is not included in the article's Creative Commons licence and your intended use is not permitted by statutory regulation or exceeds the permitted use, you will need to obtain permission directly from the copyright holder. To view a copy of this licence, visit http://creativecommons.org/licenses/by/4.0/.

\section{References}

1. Plangar I, Majlath Z, Vecsei L. Kynurenines in cognitive functions: their possible role in depression. Neuropsychopharmacol Hung. 2012;14(4):239-44.

2. Vécsei L, Szalárdy L, Fülöp F, Toldi J. Kynurenines in the CNS: recent advances and new questions. Nat Rev Drug Discov. 2013;12(1):64-82.
3. Meier TB, Drevets WC, Wurfel BE, Ford BN, Morris HM, Victor TA, et al. Relationship between neurotoxic kynurenine metabolites and reductions in right medial prefrontal cortical thickness in major depressive disorder. Brain Behav Immun. 2016;53:39-48.

4. Pellegrino AS, Cushman AJ. Stereotaxic atlas of the rat brain. New York: Plenum Press; 1979.

5. Khisti RT, Chopde CT, Jain SP. Antidepressant-like effect of the neurosteroid 3alpha-hydroxy-5alpha-pregnan-20-one in mice forced swim test. Pharmacol Biochem Behav. 2000;67(1):137-43.

6. Lapin IP. Kynurenines as probable participants of depression. Pharmakopsychiatr Neuropsychopharmakol. 1973;6(6):273-9.

7. Vécsei L, Beal MF. Influence of kynurenine treatment on openfield activity, elevated plus-maze, avoidance behaviors and seizures in rats. Pharmacol Biochem Behav. 1990;37(1):71-6.

8. Oxenkrug GF. Tryptophan-kynurenine metabolism as a common mediator of genetic and environmental Impacts in major depressive disorder: The serotonin hypothesis revisited 40 years later. Isr J Psychiatry Relat Sci. 2010;47:56-63.

9. Mándi Y, Vécsei L. The kynurenine system and immunoregulation. J Neural Transm (Vienna). 2012;119(2):197-209.

10. Höglund E, Øverli Ø, Winberg S. Tryptophan Metabolic pathways and brain serotonergic activity: a comparative review. Front Endocrinol (Lausanne). 2019;10:158.

11. Palazidou E. The neurobiology of depression. Br Med Bull. 2012;101:127-45.

12. Schwartz TL, Sachdeva S, Stahl SM. Glutamate neurocircuitry: theoretical underpinnings in schizophrenia. Front Pharmacol. 2012;3:195.

13. Kram ML, Kramer GL, Ronan PJ, Steciuk M, Petty F. Dopamine receptors and learned helplessness in the rat: an autoradiographic study. Prog Neuropsychopharmacol Biol Psychiatry. 2002;26:639-45.

14. Trullas R, Skolnick P. Functional antagonists at the NMDA receptor complex exhibit antidepressant actions. Eur J Pharmacol. 1990;185:1-10.

15. Honig A, Bartlett JR, Bouras N, Bridges PK. Amino acid levels in depression: a preliminary investigation. J Psychiatr Res. 1988;22:159-64.

16. Herman JP, Renda A, Bodie B. Norepinephrine-gamma-aminobutyric acid (GABA) interaction in limbic stress circuits: effects of reboxetine on GABAergic neurons. Biol Psychiatry. 2003;53:166-74.

17. Sanacora G, Mason GF, Rothman DL, Krystal JH. Increased occipital cortex GABA concentrations in depressed patients after therapy with selective serotonin reuptake inhibitors. Am J Psychiatry. 2002;159:663-5.

18. Luscher B, Shen Q, Sahir N. The GABAergic Deficit hypothesis of major depressive disorder. Mol Psychiatry. 2011;16(4):383-406.

19. McKernan RM, Rosahl TW, Reynolds DS, Sur C, Wafford KA, Atack JR, et al. Sedative but not anxiolytic properties of benzodiazepines are mediated by the $\mathrm{GABA}(\mathrm{A})$ receptor alpha1 subtype. Nat Neurosci. 2000;3:587-92.

20. Ogyu K, Kubo K, Noda Y, Iwata Y, Tsugawa S, Omura Y, et al. Kynurenine pathway in depression: a systematic review and metaanalysis. Neurosci Biobehav Rev. 2018;90:16-25.

Publisher's Note Springer Nature remains neutral with regard to jurisdictional claims in published maps and institutional affiliations. 